\title{
ANALISIS OPTIMALISASI WAKTU LAYANAN POTONG RAMBUT PADA TAKILISH BARBER SHOP DENGAN MODEL ANTRIAN
}

\author{
Yuliza Abidin 1 \\ Moch. Rum Alim² \\ Rahayu Lestari ${ }^{3}$ \\ ${ }^{1,2,3}$ Fakultas Ekonomi dan Bisnis Universitas Nasional \\ Email: yuliza.abidin@gmail.com ${ }^{1}, \underline{\text { rahayulestari22@yahoo.com }}^{3}$
}

\begin{abstract}
ABSTRAK
Penelitian ini bertujuan untuk menganalisis optimalisasi waktu layanan potong rambut pada Takilish Barber Shop dengan menggunakan model antrian single channel - single phase. Data primer dari observasi dan wawancara dengan pengunjung yang bersangkutan yang dipergunakan dalam penelitian ini diolah menggunakan Microsoft Excel dengan struktur antrian single channel single phase dan model antrian model A (MM/1). Hasil penelitian menunjukkan bahwa pelayanan di Takilish Barber Shop belumlah optimal, termasuk dalam hal waktu layanannya, karena tingkat pelayanan server tinggi, sehingga menyebabkan banyak waktu luang yang tidak dipergunakan secara maksimal.
\end{abstract}

Kata kunci: Optimalisasi waktu layanan, struktur antrian, model antrian, single channel single phase

\section{ABSTRACT}

This study aims to analyze the optimization of haircut service time at the Takilish Barber Shop using a single channel - single phase queue model. Primary data from observations and interviews with the concerned visitors used in this study were processed using Microsoft Excel with a single phase single channel queue structure and model A (MM/1) of queuing model. The results showed that the service at Takilish Barber Shop is not yet optimal, including in terms of service time, because of the high service level of the server, which causing a lot of free time that is not used optimally.

Keywords: Service time optimization, queuing structure, queuing model, single channel single phase

\section{PENDAHULUAN}

Barber shop atau tempat pangkas rambut merupakan salah satu tempat yang menawarkan jasa potong rambut. Dalam menggunakan jasa barber shop itu sendiri, konsumen biasanya diminta untuk menunggu dengan waktu antrian tertentu. Salah satu barber shop dengan jumlah pelanggan yang cukup banyak ialah Takilish Barber Shop. Dalam hal ini, Takilish Barber Shop menawarkan jasa spesialis potong rambut pria, yakni pada tempat yang berlokasi di Jalan Poltangan Raya. Takilish Barber Shop itu sendiri hanya memiliki satu orang petugas pelayanan yang bertugas melayani permintaan potong rambut dari konsumen dan pelanggan. Oleh karena satu orang petugas pelayanan tersebut 
dituntut untuk melayani banyak pelanggan, maka di Takilish Barber Shop itu sendiri seringkali terjadi antrian panjang yang membuat konsumen dan pelanggan yang bersangkutan diharuskan untuk menunggu dalam waktu yang cukup lama.

Menurut Heyzer dan Render (2017), teori antrian ialah suatu ilmu pengetahuan mengenai antrian (waiting line/quеue) yang mana merupakan sebaris orang ataupun barang yang menunggu untuk dilayani. Dalam hal antrian ini, Takilish Barber Shop menggunakan struktur antrian single channel - single phase dengan model antrian model A (MM/1). Hal tersebut mencerminkan bahwa di Takilish Barber Shop hanya terdapat satu loket pembayaran dan satu tahapan pelayanan yang harus dilalui oleh konsumen dan/atau pelanggannya untuk menyelesaikan pembayaran terhadap jasa potong rambut yang diterimanya.

Adapun sistem pelayanan yang dipergunakan di Takilish Barber Shop ialah first come, first served (FCFS), yakni suatu sistem pelayanan yang terlebih dahulu melayani konsumen/pelanggan yang terlebih dahulu datang daripada konsumen/pelanggan lainnya. Padahal, waktu yang dibutuhkan oleh konsumen/pelanggan seringkali bersifat random dan tidak sama dengan waktu yang dibutuhkan oleh konsumen/pelanggan lainnya. Dalam kegiatan operasionalnya, Takilish Barber Shop juga menerapkan beberapa Standard Operating Procedure (SOP) yang salah satunya ialah menetapkan waktu maksimal dalam memberikan pelayanan kepada konsumen, yakni maksimal selama 30 menit untuk setiap konsumen yang melakukan potong rambut.

Berdasarkan latar belakang di atas, perlu dilakukan penelitian untuk menganalisis optimalisasi waktu layanan potong rambut pada Takilish Barber Shop dengan menggunakan model antrian single channel - single phase. Dalam kaitannya dengan hal tersebut, perlu pula dilakukan analisis terhadap waktu rata-rata pelayanan yang diperlukan konsumen/pelanggan, tingkat kejenuhan (batas waktu tunggu maksimal pelanggan), dan panjang antrian yang optimal.

\section{TINJAUAN PUSTAKA}

\section{Waktu Layanan}

Menurut Kotler dan Keller (2009:42), jasa (service) atau yang dapat juga diartikan sebagai pelayanan adalah tindakan ataupun kegiatan yang ditawarkan oleh satu pihak kepada pihak lainnya yang tidak berwujud dan tidak menimbulkan kepemilikan atas sesuatu, serta produksinya bisa atau tidak bisa dihubungkan dengan suatu produk fisik. 
Mayangsari dan Prastiwi (2016) menyebutkan bahwa waktu yang dipergunakan untuk melayani individu dalam suatu sistem disebut juga sebagai waktu pelayanan. Waktu pelayanan dapat mengikuti distribusi eksponensial, tetapi dapat juga mengikuti distribusi Poisson jika terdistribusi acak.

\section{Pengertian Antrian}

Teori antrian ialah suatu ilmu pengetahuan mengenai antrian (waiting line/queиe) yang mana merupakan sebaris orang ataupun barang yang menunggu untuk dilayani (Heyzer dan Render, 2017). Menurut Kakiay (2004), antrian merupakan suatu kegiatan dimana konsumen menunggu untuk menerima suatu pelayanan. Adapun Dimyati dan Dimyati (2009:349) mendefinisikan antrian sebagai suatu teori terkait studi matematis dari antrian ataupun barisan yang menunggu. Dalam Jatmika dan Prasetyo (2017) juga disebutkan bahwa teori antrian itu sendiri bertujuan untuk mengurangi biaya yang ditimbulkan oleh antrian.

Antrian itu sendiri merupakan bagian penting dari suatu kegiatan operasional perusahaan. Analisis terhadap antrian dalam hal panjangnya antrian, rata-rata waktu tunggu, dan berbagai faktor lain yang terkait dapat membantu perusahaan, mulai dari yang bergerak di bidang manufaktur maupun jasa, dalam memahami sistem pelayanan, aktivitas maintenance, dan bahkan aktivitas pengawasan toko (Heizer, et al., 2017).

\section{Karakteristik Sistem Antrian}

Ada tiga karakteristik dari suatu sistem antrian sebagaimana yang dikemukakan oleh Heizer, et al. (2017), yakni sebagai berikut.

1. Kedatangan atau Input Sistem

Dalam hal ini, suatu kedatangan atau input sistem memiliki karakteristik yang mencakup ukuran dari populasi kedatangan, perilaku kedatangan, dan pola kedatangan (distribusi statistik).

a. Ukuran dari Populasi Kedatangan

Ukuran dari populasi kedatangan dapat dibedakan menjadi ukuran yang terbatas dan tidak terbatas. Dalam hal ini, jika jumlah pelanggan atau kedatangan pada suatu waktu tertentu hanyalah sebagian kecil dari seluruh kedatangan potensial, maka populasi kedatangan dapat dinilai berukuran tak terbatas. Dengan kata lain, populasi kedatangan yang tidak terbatas adalah suatu antrian dimana orang ataupun 
barang dengan jumlah yang tak terbatas dapat meminta suatu jasa. Adapun yang dimaksud dengan populasi kedatangan yang terbatas adalah suatu antrian dimana hanya ada sejumlah pengguna potensial tertentu yang terbatas dari suatu jasa.

b. Pola Kedatangan

Pola kedatangan dapat dibedakan menjadi pola konstan dan acak (random). Suatu kedatangan itu sendiri dinyatakan acak jika pola kedatangannya tersebut independen dan kejadiannya tidak bisa diprediksi secara tepat. Dalam berbagai kasus antrian, jumlah kedatangan per unit waktu dapat diestimasikan dengan menggunakan distribusi Poisson.

c. Perilaku Kedatangan

Sebagian besar model antrian mengasumsikan bahwa pelanggan yang datang adalah pelanggan yang sabar (patient customer), yakni pelanggan yang menunggu dalam antrian hingga mereka disajikan dengan tanpa berpindah garis antrian. Ada juga yang disebut sebagai reneging customer, yakni pelanggan yang memasuki antrian tetapi tidak sabar, sehingga akhirnya meninggalkan antriannya tersebut dengan tanpa menyelesaikan transaksinya.

\section{Disiplin Antrian}

Disiplin antrian atau antrian itu sendiri memiliki karakteristik yang mencakup panjangnya antrian dan disiplin orang ataupun barang yang ada di dalam antrian itu sendiri. Panjangnya suatu antrian dapat dibedakan menjadi terbatas dan tidak terbatas. Dalam hal ini, suatu antrian memiliki panjang yang terbatas jika antrian tersebut tidak dapat diperpanjang ke suatu tingkat tertentu, baik dikarenakan oleh factor hukum atau bahkan restriksi fisik. Adapun antrian yang tidak terbatas ialah suatu antrian yang panjangnya tidak terbatas, seperti dalam kasus pintu tol yang melayani kedatangan mobil-mobil dalam jumlah yang tidak terbatas.

Disiplin antrian juga dapat diartikan sebagai suatu pedoman yang mengatur mengenai pelanggan mana yang akan menerima jasa dalam suatu antrian. Disiplin antrian yang umumnya dipergunakan ialah aturan First-In First-Out (FIFO), yakni suatu aturan dimana pelanggan yang pertama kali datanglah yang akan dilayani terlebih dahulu. Adapun aturan disiplin antrian lainnya antara lain mencakup aturan Shortest Operating Service Time (SOT), yakni waktu operasi layanan terpendek; LastIn First-Out (LIFO), yakni suatu aturan dimana pelanggan yang terakhir kali datanglah 
yang dilayani terlebih dahulu; Longest Operating Time (LOT), yakni waktu operasi terpanjang; dan Service In Random Order (SIRO), yani layanan dalam urutan yang acak.

3. Fasilitas Jasa

Fasilitas jasa disini memiliki karakteristik yang mencakup desain dan distribusi statistik dari waktu pelayanan. Dalam hal desain, sistem antrian biasanya dibagi berdasarkan banyaknya server (channel) dan banyaknya phase (service stop yang harus dilewati). Berdasarkan hal tersebut, ada empat desain sistem antrian dasar yang umum dipergunakan, yakni sebagai berikut.

a. Single Channel-Single Phase

Dalam desain antrian ini, hanya ada satu jalur antrian dan satu tahap pelayanan. Maksud dari satu jalur antrian (single channel) disini ialah hanya ada satu jalur antrian untuk menuju ke tempat pelayanan, sehingga pelanggan harus melalui jalur tersebut. Adapun maksud dari satu tahap pelayanan (single phase) ialah pelanggan hanya diharuskan untuk melawati satu tahap pelayanan saja.

b. Single Channel-Multi Phase

Dalam desain antrian ini, hanya ada satu jalur antrian dan dua tahap pelayanan. Dua tahap pelayanan (multi phase) yang dimaksudkan disini menunjukkan bahwa ada dua tahap pelayanan yang harus dilewati oleh konsumen ataupun pelanggan secara tidak bersamaan, dimaana pelayanan tahap 1 harus terlebih dahulu diselesaikan sebelum lalu melanjutkan ke pelayanan tahap 2.

c. Multi Channel-Single Phase

Dalam desain antrian ini, terdapat lebih dari dua jalur antrian dan satu proses tahapan pelayanan. Maksud dari multi channel disini ialah konsumen atau pelanggan dapat mempergunakan lebih dari dua jalur antrian untuk melewati suatu proses dari tahap pelayanan. Hal tersebut menunjukkan bahwa pelanggan dapat berpindah jalur antrian ke jalur yang bergerak lebih cepat. Akan tetapi, pelanggan tidak dapat berpindah tahap karena dalam desain tahapan proses pelayanan dalam struktur antrian ini hanya terdapat satu tahap (single phase), sehingga meskipun jalurnya berbeda, tahapan proses pelayaan yang dilewati sama saja. 


\section{d. Multi Channel-Multi Phase}

Dalam desain antrian ini, ada lebih dari satu jalur antrian dan lebih dari satu tahapan proses pelayanan. Akibatnya, pelanggan hanya dapat berpindah jalur dan tidak dapat berpindah tahap pelayanan jika tahap pelayanan satu di jalur antrian manapun belum terselesaikan. Setelah menyelesaikan tahap satu pelayanan, barulah pelanggan dapat melanjutkan ke tahap dua pelayanan. Artinya, tahap pelayanan dua tidak dapat dilakukan jika tahap pelayanan pertama belum diselesaikan.

Adapun dalam hal karakteristik lainnya pada fasilitas jasa, yakni dalam hal distribusi statistik dari waktu pelayanan, pola pelayanan dapat dibedakan sebagaimana halnya pada pola kedatangan, yakni menjadi pola konstan dan acak. Apabila waktu pelayanan konstan, maka lamanya waktu yang dipergunakan untuk melayani setiap pelanggan adalah sama. Meskipun demikian, waktu pelayanan itu sendiri lebih sering terdistribusi secara acak.

\section{Model Antrian}

Heizer, et al. (2017) mengemukakan bahwa ada empat model antrian yang umumnya dipergunakan oleh perusahaan berdasarkan asumsi kedatangan yang terdistribusi Poisson, disiplin FIFO, dan single-service phase, yakni sebagai berikut.

1. Model A (M/M/1): Single-channel queuing model with poisson arrivals and exponential service times, yakni model antrian saluran tunggal dengan kedatangan poisson dan waktu layanan eksponensial.

$$
\lambda=\frac{\mathrm{N}}{\text { Jumlah waktu antarkedatangan }}
$$

Keterangan:

$\lambda=$ Tingkat kedatangan

$$
\mu=\frac{\mathrm{N}}{\text { Jumlah Pelayanan }}
$$

Keterangan:

$$
\mu=\text { Tingkat pelayanan }
$$




$$
\mathrm{Ls}=\frac{\lambda}{\mu-\lambda}
$$

Keterangan:

Ls = Rata-rata yang antri dalam sistem

$$
\operatorname{La}=\frac{\lambda^{2}}{\mu(\mu-\lambda)}
$$

Keterangan:

$\mathrm{La}=$ Rata-rata yang antri dalam antrian

$$
p_{n}=\left(\frac{\lambda}{\mu}\right) \quad n\left(1-\left(\frac{\lambda}{\mu}\right)\right)
$$

Keterangan:

$\mathrm{Pn}=$ Peluang terjadinya jumlah pelanggan dalam antrian

$$
\text { Ws }=\frac{1}{\mu-\lambda}
$$

Keterangan:

Ws = Rata-rata waktu menunggu dalam sistem

$$
W_{a}=\frac{\lambda}{\mu(\mu-\lambda)}
$$

Keterangan:

$\mathrm{Wa}=$ Rata-rata waktu menunggu dalam antrian

$$
\mathrm{K}=\frac{\lambda}{\mu}
$$

Keterangan:

$\mathrm{K}=$ Tingkat kesibukan server

$$
\mathrm{W}=100 \%-\mathrm{K}
$$

Keterangan:

$\mathrm{W}=$ Tingkat pengangguran server

2. Model B (M/M/S): Multiple-Channel Queuing Model, yakni model antrian yang memiliki dua atau lebih jalur stasiun pelayanan dengan asumsi kedatangan mengikuti distribusi eksponensial. 


$$
\mathrm{x}=\frac{\text { Total Konsumen per periode yang sama }}{\text { Total periode waktu }}
$$

Keterangan:

$\lambda=$ Rata-rata tingkat kedatangan

$$
\mu=\frac{\text { Total kedatangan }}{\text { Total jam kerja }}
$$

Keterangan:

$\mu=$ Rata-rata tingkat pelayanan

$$
\mathrm{Po}=\frac{1}{\left[\sum_{n=0}^{M-1} \frac{1}{n}\left(\frac{\lambda}{\mu}\right)^{n}\right]+\frac{1}{M !}\left(\frac{\lambda}{\mu}\right)^{2} \frac{M(\mu)}{M(\mu)-\lambda}}
$$

Keterangan:

Po $=$ Probabilitas terdapat 0 orang dalam sistem

$$
\mathrm{p}=\frac{\lambda}{M \lambda}
$$

Keterangan:

$\mathrm{p}=$ Tingkat utilitas kasir

$$
\mathrm{Ls}=\frac{\lambda \mu\left(\frac{\lambda}{\mu}\right)^{m}}{(M-1) !(M \mu-\lambda)^{2}} P_{o}+\frac{\lambda}{\mu}
$$

Keterangan:

Ls = Jumlah konsumen rata-rata dalam sistem

$$
\mathrm{Ws}=\frac{L_{s}}{\lambda}
$$

Keterangan:

Ws $=$ Waktu rata-rata yang dihabiskan seorang konsumen dalam sistem

$$
\mathrm{Lq}=\mathrm{Ls}-\frac{\lambda}{\mu}
$$

Keterangan:

$\mathrm{Lq}=$ Jumlah orang atau unit rata-rata yang menunggu dalam antrian

$$
\mathrm{Wq}=\frac{L q}{\mathrm{x}}
$$


Keterangan:

$\mathrm{Wq}=$ Waktu rata-rata yang dihabiskan oleh seorang konsumen dalam antrian

3. Model C (M/D/1): Constant-Service-Time Model, yakni model antrian dengan waktu konstan.

$$
\mathrm{Lq}=\frac{x^{2}}{2 \mu(\mu-\lambda)}
$$

Keterangan:

$\mathrm{Lq}=$ Jumlah orang atau unit rata-rata yang menunggu dalam antrian

$$
\mathrm{Wq}=\frac{\lambda}{2 \mu(\mu-\lambda)}
$$

Keterangan:

$\mathrm{Wq}=$ Waktu rata-rata yang dihabiskan oleh seorang konsumen dalam antrian

$$
\mathrm{Ls}=\mathrm{Lq}+\frac{\lambda}{\mu}
$$

Keterangan:

Ls $=$ Jumlah konsumen rata-rata dalam sistem

$$
\mathrm{Ws}=\mathrm{Wq}+\frac{1}{\mu}
$$

Keterangan:

Ws $=$ Waktu rata-rata yang dihabiskan seorang konsumen dalam sistem

4. Model D (M/M/1 with finite source): finite-population model, yakni suatu model antrian yang di dalamnya terdapat hubungan ketergantungan antara panjang antrian dan tingkat kedatangan.

Keterangan:

$$
\mathrm{L}=\mathrm{N}(1-\mathrm{F})
$$

$\mathrm{X}=$ Faktor pelayanan

$\mathrm{L}=$ Rata-rata orang dalam menunggu pelayanan

$$
\mathrm{w}=\frac{L(T+U)}{N-L}=\frac{T(1-F)}{X F}
$$


Keterangan:

$\mathrm{W}=$ Rata-rata waktu menunggu

$\mathrm{T}=$ Rata-rata waktu pelayanan

$\mathrm{U}=$ Waktu rata-rata antara persyaratan layanan unit

$\mathrm{X}=$ Faktor pelayanan

$$
\mathrm{J}=\mathrm{NF}(1-\mathrm{X})
$$

Keterangan:

$\mathrm{J}=$ Rata-rata jumlah pelayanan yang sedang berlangsung

$$
\mathrm{H}=\mathrm{FNX}
$$

Keterangan:

$\mathrm{H}=$ Jumlah rata-rata di layani

$$
\mathrm{N}=\mathrm{J}+\mathrm{L}+\mathrm{H}
$$

Keterangan:

$\mathrm{N}=$ Jumlah populasi

\section{Kinerja Antrian}

Menurut Heizer, et al. (2017), model antrian pada dasarnya bisa membantu manajer dalam mengambil suatu keputusan yang dapat menyeimbangkan biaya pelayanan dan biaya antrian. Analisis antrian dalam hal ini, dapat menghasilkan berbagai ukuran kinerja dari suatu antrian, yang di antaranya mencakup hal-hal sebagai berikut.

1. Waktu rata-rata yang di habiskan oleh pelanggan dalam antrian

2. Waktu rata-rata yang di habiskan oleh pelanggan dalam sistem (waktu tunggu di tambah waktu pelayanan).

3. Jumlah pelanggan rata-rata dalam sistem.

4. Probabilitas fasilitas pelayanan akan kosong.

\section{METODOLOGI PENELITIAN}

\section{Objek Penelitian}

Objek dalam penelitian ini adalah optimalisasi pelayanan potong rambut pada Takilish Barber Shop yang menjadi subjek penelitian. Adapun penelitian ini digolongkan 
sebagai studi kasus atau jenis penelitian lapangan. Berdasarkan hal tersebut, maka populasi dari penelitian ini ialah seluruh pelanggan Takilish Barber Shop.

\section{Sumber dan Jenis Data}

Penelitian ini mempergunakan data primer berjenis kuantitatif yang diperoleh dari observasi dan wawancara dengan pengunjung yang datang ke Takilish Barber Shop. Data tersebut kemudian diolah dengan menggunakan Microsoft Excel.

\section{Metode Analisis}

Dalam penelitian ini, optimalisasi pelayanan diukur dengan menggunakan fungsi sebagai berikut.

$$
\mathbf{Y}=\mathbf{F}\left(X_{1}, X_{2}, X_{3}\right)
$$

Keterangan:

$$
\begin{aligned}
& \mathrm{Y}=\text { Optimalisasi pelayanan } \\
& X_{1}=\text { Waktu tunggu } \\
& X_{2}=\text { Waktu pelayanan } \\
& X_{3}=\text { Waktu pembayaran }
\end{aligned}
$$

Desain antrian yang dipergunakan adalah single channel single phase, yakni desain antrian yang hanya memiliki satu jalur antrian dan satu jalur pelayanan. Adapun model antrian yang dipergunakan adalah model A (M/M/1): Single-channel queuing model with poisson arrivals and exponential service times, yakni model antrian saluran tunggal dengan kedatangan poisson dan waktu layanan eksponensial.

Dalam penelitian ini, antrian didefinisikan sebagai orang atau waktu yang berada dalam sebuah antrian untuk menunggu mendapatkan pelayanan, tetapi belum sampai pada tahap pelayanan. Adapun yang dimaksudkan dengan sistem adalah orang atau waktu yang berada dalam sebuah sistem yang di dalamnya sudah termasuk antrian dan pelayanan.

\section{HASIL PENELITIAN DAN PEMBAHASAN}

Berdasarkan hasil observasi selama 27 hari kerja, yakni pada 1 Desember 2018 s.d. 31 Desember 2018, diperoleh data sebagai berikut. 
Tabel 1. Total Waktu Tunggu, Waktu Pelayanan, dan Waktu Pembayaran

\begin{tabular}{|l|r|}
\hline \multicolumn{1}{|c|}{ Jenis Waktu } & \multicolumn{2}{|c|}{ Total Waktu } \\
\hline Waktu Tunggu & 21.157 \\
\hline Waktu Pelayanan & 9.270 \\
\hline Waktu Pembayaran & 795 \\
\hline (Sumber: Data primer diolah, 2019)
\end{tabular}

Tabel 2. Rata-Rata dari Waktu Tunggu, Waktu Pelayanan, dan Waktu Pembayaran

\begin{tabular}{|l|c|}
\hline \multicolumn{1}{|c|}{ Jenis Waktu } & Rata-Rata Waktu \\
\hline Waktu Tunggu & 75,2192 \\
\hline Waktu Pelayanan & 34,2037 \\
\hline Waktu Pembayaran & 2,97407 \\
\hline
\end{tabular}

(Sumber: Data primer diolah, 2019)

Tabel 3. Waktu Maksimal dari Waktu Tunggu, Waktu Pelayanan, dan Waktu Pembayaran

\begin{tabular}{|c|c|}
\hline Jenis Waktu & Waktu Maksimal \\
\hline Waktu Tunggu & 231 \\
\hline Waktu Pelayanan & 45 \\
\hline Waktu Pembayaran & 9 \\
\hline
\end{tabular}

(Sumber: Data primer diolah, 2019)

Tabel 4. Waktu Minimal dari Waktu Tunggu, Waktu Pelayanan, dan Waktu Pembayaran

\begin{tabular}{|c|c|}
\hline Jenis Waktu & Waktu Minimal \\
\hline Waktu Tunggu & 32 \\
\hline Waktu Pelayanan & 30 \\
\hline Waktu Pembayaran & 2 \\
\hline
\end{tabular}

(Sumber: Data primer diolah, 2019)

\section{1. $\lambda$ dan $\mu$}

Berikut ini merupakan data yang dipergunakan untuk menghitung $\lambda$ dan $\mu$.

Total Pelanggan $(\mathrm{N})$

Total Waktu Antar Kedatangan

Total Waktu Pelayanan

$$
\begin{aligned}
& =272 \\
& =12.138 \\
& =9.270
\end{aligned}
$$

Dengan menggunakan data di atas, model A (M/M/1), dan sistem antrian Single Channel - Single Phase, diperoleh nilai ג dan $\mu$ sebagai berikut. 


$$
\begin{aligned}
& \lambda=\frac{\mathrm{N}}{\text { Total waktu antarkedatangan }} \\
& \lambda=\frac{272}{12.138}=0,0224
\end{aligned}
$$

$$
\begin{aligned}
& \mu=\frac{\mathrm{N}}{\text { Total Waktu Pelayanan }} \\
& \mu=\frac{272}{9.270}=0,0293
\end{aligned}
$$

\section{Rata - Rata yang Antri dalam Sistem $\left(L_{s}\right)$}

$$
\begin{aligned}
& L_{s}=\frac{\lambda}{\mu-\lambda} \\
& L_{s}=\frac{0,0224}{0,0293-0,0224} \\
& L_{s}=\frac{0,0224}{0,0069} \\
& L_{s}=3,246
\end{aligned}
$$

Berdasarkan perhitungan di atas, diperoleh nilai $L_{s}$ sebesar 3,246 atau di bulatkan menjadi 3. Hal tersebut menunjukkan bahwa rata-rata banyaknya pelanggan yang berada dalam system di Takilish Barber Shop adalah 3 orang.

\section{Rata-Rata yang Antri dalam Antrian $\left(L_{a}\right)$}

$$
\begin{aligned}
& L_{a}=\frac{\lambda^{2}}{\mu(\mu-\lambda)} \\
& L_{a}=\frac{0,0224^{2}}{0,0293(0,0293-0,0224)} \\
& L_{a}=\frac{0,00050176}{0,0293(0,0069)} \\
& L_{a}=\frac{0,00050176}{0,00020217} \\
& L_{a}=2,48
\end{aligned}
$$


Berdasarkan perhitungan di atas, diperoleh nilai $L_{a}$ sebesar 2,48 atau 2 . Hal tersebut menunjukkan bahwa rata-rata banyaknya pelanggan yang berada dalam antrian di Takilish Barber Shop adalah 2 orang.

\section{Peluang Terjadinya Jumlah Pelangggan dalam Antrian $\left(P_{n}\right)$}

$$
\begin{aligned}
& \left(P_{n}\right)=\left(\frac{\lambda}{\mu}\right)^{3}\left(2-\left(\frac{\lambda}{\mu}\right)\right) \\
& \left(P_{n}\right)=\left(\frac{0,0224}{0,0293}\right)^{3} 2\left(2-\left(\frac{0,0224}{0,0293}\right)\right) \\
& \left(P_{n}\right)=(0,764)^{3}(2-(0,764)) \\
& \left(P_{n}\right)=(0,4459)(1,236) \\
& \left(P_{n}\right)=0,551
\end{aligned}
$$

Keterangan :

$\mathrm{N}=$ Banyaknya orang yang antri dalam antrian yang mana diperoleh dari nilai $L_{a}$

$$
\mathrm{N}=2
$$

Nilai $P_{n}$ di atas menunjukkan bahwa besarnya peluang terjadinya jumlah pelanggan dalam antrian di Takilish Barber Shop adalah 55,1\%.

\section{Rata-Rata Waktu Menunggu dalam Sistem $\left(W_{s}\right)$}

$$
\begin{aligned}
& W_{S}=\frac{1}{\mu-\lambda} \\
& W_{S}=\frac{1}{0,0293-0,0224}=\frac{1}{0,0069}=144,972
\end{aligned}
$$

Nilai $W_{s}$ sebesar 144,972 menit menunjukkan bahwa waktu rata-rata menunggu dalam sistem di Takilish Barber Shop adalah \pm 145 menit atau setara dengan 2 jam lebih 25 menit. 


\section{Rata-Rata Waktu Menunggu dalam Antrian ( $\left.W_{a}\right)$}

$$
\begin{aligned}
& W_{a}=\frac{\lambda}{\mu(\mu-\lambda)} \\
& W_{a}=\frac{0,0224}{0,0293(0,0293-0,0224)} \\
& W_{a}=\frac{0,0224}{0,0293(0,0069)}=110,797
\end{aligned}
$$

Nilai $W_{a}$ sebesar 110,797 menit menunjukkan bahwa waktu rata-rata menunggu dalam antrian di Takilish Barber Shop adalah \pm 111 menit atau setara dengan 1 jam lebih 51 menit.

\section{Tingkat Kesibukan Server ( K )}

$$
\begin{aligned}
& \mathrm{K}=\frac{\lambda}{\mu} \\
& \mathrm{K}=\frac{0,0224}{0,0293}=0,764
\end{aligned}
$$

Berdasarkan perhitungan di atas, maka tingkat kesibukan server di Takilish Barber Shop adalah $76,4 \%$.

\section{Tingkat Pengangguran Server ( W )}

$$
\begin{aligned}
& \mathrm{W}=100 \%-\mathrm{K} \\
& \mathrm{W}=100 \%-76,4 \% \\
& \mathrm{~W}=23,6 \%
\end{aligned}
$$

Berdasarkan perhitungan di atas, maka tingkat pengangguran server di Takilish Barber Shop adalah 23,6\%.

\section{KESIMPULAN DAN SARAN}

\section{Kesimpulan}

Berdasarkan hasil penelitian ini, dapat disimpulkan bahwa pelayanan di Takilish Barber Shop masih belum optimal karena tingkat pengangguran server-nya masih cukup besar, yakni sebesar 23,6 \%. Realisasi waktu pelayanan per setiap pelanggannya pun cukup lama, yakni 34 menit per orang (waktu pelayanan/jumlah pelanggan $=9.270 / 272=$ 34 menit), sementara waktu pelayanan yang ditargetkan oleh Takilish Barber Shop dalam SOP-nya adalah 30 menit per orang. Hal tersebut menunjukkan bahwa waktu realisasi 
pelayanan yang diberikan kepada setiap pelanggan lebih lama 4 menit dari waktu pelayanan yang ditargetkan dalam SOP yang dimaksud karena kurang optimalnya penggunaan waktu yang ada. Dalam satu bulan, banyaknya waktu yang tidak dipergunakan secara maksimal oleh Takilish Barber Shop berarti adalah 1.088 menit (4 menit x 272 pelanggan). Idealnya, waktu yang tidak dipergunakan secara maksimal tersebut justru dapat dimanfaatkan secara maksimal untuk melayani sebanyak 36 orang per bulan (1.088 menit : 30 menit).

\section{Saran}

Berdasarkan kesimpulan di atas, berikut ini diberikan saran yang dapat dipertimbangkan oleh pihak terkait.

1. Meningkatkan keahlian barber- nya sehingga tercipta pelayanan yang cepat, andal, dan dapat memuaskan pelanggan setia Takilish Barber Shop.

2. Menambah jumlah barbernya, tetapi dengan kesiapan untuk menanggung risiko terkait, misalnya karena setiap barber memiliki ciri khas tersendiri dalam memotong rambut, maka perlu diadakan pelatihan bagi barber yang baru.

\section{DAFTAR PUSTAKA}

Agyei, Wallace., C.A Darko, dan F. Odilon. 2015. Modeling and Analysis of Queuing Systems in Branks: A Case Study of Ghana Commercial Bank Ltd. Kumasi Main Branch. International Journal of Scientific and Technology Research. 4(7): 160163.

Dimyati, T. dan A. Dimyati. 2009. Operations Research: Model-Model Pengambilan Keputusan. PT Sinar Baru Algensindo. Bandung.

Heizer, J., B. Render, dan C. Munson. 2017. Operations Management: Sustainability and Supply Chain Management. Twelfth Edition. Pearson Education. Boston.

Jatmika, S. dan B. P. T. Prasetyo. 2017. Analisis Antrian Model Multi Channel - Single Phase dan Optimalisasi Layanan Akademik: Studi Kasus pada STMIK Asia Malang. Jurnal Positif. 3(1): 41-46.

Kakiay, T.J. 2004. Pengantar Sistem Simulasi. Andi. Yogyakarta.

Kotler, P. dan K.L. Keller. 2006. Marketing Management. $12^{\text {th }}$ Edition. Prentice Hall. New Jersey. Terjemahan Tim Indeks. 2009. Manajemen Pemasaran. Edisi 12. PT Indeks. Jakarta. 
Krajewski, L.J., M.K. Malhotra., dan L.P. Ritzman. 2016. Operations Management: Processes and Supply Chains. $11^{\text {th }}$ Edition. Global Edition. Pearson Education. Harlow.

Mayangsari, Y. dan E.H. Prastiwi. 2016. Sistem Antrian Teller Bank Mandiri sebagai Upaya Meningkatkan Efisiensi Kecepatan Transaksi. Jurnal Ekonomi dan Bisnis. 1(1): 49-60.

Nurfitria, D., Nur'Eni, dan I.T. Utami. 2017. Analisis Antrian Dengan Model Single Channel Single Phase Service pada Stasiun Pengisisan Bahan Bakar Umum I Gusti Ngurah Rai Palu. Jurnal Scientific Pinisi. 3(1): 65 -71.

Russel, R.S. dan B.W. Taylor. 2011.Operations Management Creating Value Along the Supply Chain. $7^{\text {th }}$ Edition. John Wiley \& Sons. New York.

Stevenson, W.J. dan S.C. Chuong. 2014. Operations Management. $2^{\text {nd }}$ Edition. Asia Global Edition. McGraw-Hill. New York. 